rich in food and the effects of trade goods had a large hand in the two processes. His own explanatory sketches are a way of saying "I have as good if not better imagination than the next archaeologist; so believe my story!" - except that he continues to throw down those challenges to develop methodology in order to make reliable inferences rather than inspired judgements on the archaeological record. Although Binford has concentrated his research among hunters and gatherers, these forays into later prehistory point out very neatly that archaeological inference does not get easier as life became more complex and hence closer in appearance to our own cultural experience.

Many archaeologists have been hoping that Binford would write an accessible book of this nature. With the assistance of the collaborative editors, John Cherry and Robin Torrence, this text has captured one man's enthusiasm for his research as it was delivered in lectures in England and the Netherlands. It carries his classic stylistic trademarks including some coruscating footnotes, unmistakable line drawings, new additions to archaeological vocabulary and above all a willingness to confront archaeology's big problems head on. No one can read this book without acknowledging that archaeology is finally digging up its nineteenth century roots and burning them. Lewis Binford shows, by example, the strategies that are needed to turn the subject from a backward-looking curiosity into a scientific attack on our understanding of past human behaviour. $\square$

Clive Gamble is a Lecturer in the Department of Archaeology at the University of Southampton.

Journals' review issue 1983

On October 6th Nature will publish the third review supplement devoted to science journals. The two previous supplements (covering journals first published between January 1978 and May 1980, and June 1980 and May 1981) appeared in Nature 293, 341-369 (1981) and 299, 491-514 (1982).

Criteria for inclusion of a journal in the 1983 issue are that:

- the first number appeared, or the journal was re-titled, between June 1981 and May 1982;

- it is published at least three times a year;

- the main language used is English.

Broadly, periodicals of professional interest to scientists will be considered for review, with the exception of abstracts' journals. Journals appearing prior to June 1981 but after January 1978, and not covered in the previous issues, will also be considered.

Publishers and societies are invited to submit four sample issues of journals satisfying the above criteria, including the first and most recent numbers, to the Review Editor, Nature, 4 Little Essex St, London WC2R 3LF, England.

\section{Condensed matters for the expert}

\section{P.N. Butcher}

The Structure and Properties of Matter.

Edited by T. Matsubara.

Springer-Verlag: 1983. Pp.432.

DMI00, $\$ 40$.

IT is a brave author who sets out in the last quarter of the twentieth century to describe the modern theory of condensed matter from a unified point of view. He needs help. He needs skill in selecting which topics to include and which to leave out. Above all he needs to define his audience carefully. Failure on any of these counts will mean either that the work is never finished or that no one will read it when it is.

With the expert help of Professors Tsuneto, Murao, Matsuda and Yonesawa, Professor Matsubara has successfully avoided all these traps for the unwary. He and his co-authors present essentially simple but tightly knit arguments which start from the first principles of quantum and statistical mechanics and gently guide the reader towards the modern view of matter. In the beginning there are electrons and nuclei. At the end there are metals, semiconductors, superfluids, ferromagnetics, crystals and glasses. It is a fascinating journey but not one to be undertaken lightly by the reader. He needs to keep his wits about him to see all the navigational aids provided as they flash rapidly past in the brief span of $\mathbf{4 3 2}$ pages.

Generality must be the keynote in a book like this and it is admirably maintained throughout. Particular materials and experiments are described only when they illustrate the theoretical concepts which are the chief concern of the authors. For the most part these are the ideas which occupied the centre of the stage when the first edition appeared in Japan in 1973: band structure, superfluids, magnetic materials, the Kondo effect and disordered systems. The present volume is a translation of a revised edition published in 1978.

The book is written in a simple style by experts. It is intended to be read for pleasure by experts, and they will enjoy the succinct way in which the authors handle the intricate problems which they take up. Students should look elsewhere. The treatment is very concise and the reference lists are short, most of the citations being to material published before 1975 which is already beginning to seem quite a long time ago. The weight given to different topics also reflects the fashions of the early 1970 s. There are separate chapters on ${ }^{4} \mathrm{He}$ and ${ }^{3} \mathrm{He}$ and another on the Kondo effect. On the other hand superconductors get only ten pages and Anderson localization is given just one page in a chapter on random systems.

The authors have rigorously excluded some topics in order to be able to write at reasonable length about others. Electron transport phenomena are the most regrettable omission. This has been a fruitful field over the past 15 years, both in Japan and elsewhere, and it is disappointing not to find some reference to it here. Less serious is the omission of treatments of $\mathrm{X}$-ray, electron and neutron diffraction studies of atomic structure and of the thermal properties of condensed matter. These are readily available elsewhere. By leaving them out the authors have been able to write extensive accounts of both pseudopotential and tight-binding band structure methods, and of the coherent potential approximation, which are at once both excellent and timeless.

P.N. Butcher is Professor of Theoretical Physics at the University of Warwick.

\section{Reference: mine as a mountain}

\section{Alan Isaacs}

Van Nostrand's Scientific Encyclopedia, 6th Edn.

Edited by Douglas M. Considine.

Van Nostrand Reinhold: 1983. Pp.3,067. \$107.50, £95.

THE reappearance of Van Nostrand's Scientific Encyclopedia in a new edition (the sixth) only seven years after the last edition, combined with its sheer bulk $(3,067$ pages, 700 more than the fifth edition), provides welcome reassurance that this very considerable work is now a permanent feature of the scientific landscape - the Mont Blanc, if not the Everest (the 15-volume McGraw-Hill Encyclopedia of Science and Technology is surely that), of scientific encyclopaedias.

Because I do not believe that a reviewer is entitled to denigrate in a few brash sentences a work that has taken a number of people several years to produce, I would not say that this encyclopaedia was awful even if I thought so. As it happens, the book is undoubtedly a mine of very useful information, particularly in the newer and more exciting areas of science and technology. Much of this information would be hard to unearth in such a concise form elsewhere. I do, however, have two reservations.

The first is that the book has a very heavy American bias, probably unnecessarily so. Technological examples, end-of-article bibliographies and illustrations of equipment are all almost exclusively American. Even if the American parish is the biggest and most influential in the whole scientific congregation, a reference work such as this 